\title{
The spike glycoprotein genes of porcine epidemic diarrhea viruses isolated in China
}

\author{
Pei-Hua Wang ${ }^{1 \dagger}$, Ya-Qian Li ${ }^{1 \dagger}$, Yuan-Qing Pan ${ }^{1 \dagger}$, Yan-Yan Guo ${ }^{1 \dagger}$, Fan Guo ${ }^{1,2,3}$, Rui-Zhu Shi ${ }^{1,2,3}$ and Li Xing ${ }^{1,2,3^{*}}$ (1)
}

\begin{abstract}
The porcine epidemic diarrhea virus (PEDV) causes a highly contagious disease in pigs, which is one of the most devastating viral diseases of swine in the world. In China, PEDV was first confirmed in 1984 and PEDV infections occurred sporadically from 1984 to early 2010. From late 2010 until present, PEDV infections have swept every province or region in China. In this study, we analyzed a total of 186 full-length spike genes and deduced proteins of all available complete genomes of PEDVs isolated in China during 2007-2019. A total of 28 potential recombination events were identified in the spike genes of PEDVs in China. Spike gene recombination not only expanded the genetic diversity of PEDVs in the Gll genogroup, but also resulted in the emergence of a new evolutional branch Gl-c during 2016-2018. In addition, comparative analysis of spike proteins between Gl-a prototype virulent CV777 and GII strain AJ1 102 reveals that the amino acid variations could affect 20 potential linear B cell epitopes, demonstrating a dramatic antigen drift in the spike protein. These results provide a thorough view of the information about the genetic and antigenic diversity of PEDVs circulating in China and therefore could benefit the development of suitable strategies for disease control.
\end{abstract}

Keywords: Porcine epidemic diarrhea virus (PEDV), Phylogenetic analysis, Recombination, B cell epitope, Spike glycoprotein, China

\section{Introduction}

Porcine epidemic diarrhea (PED) is caused by porcine epidemic diarrhea virus (PEDV) [1]. PED is characterized by severe watery diarrhea, vomiting, anorexia, dehydration, and weight loss in pigs [1]. PEDV is highly contagious and infects pigs of all ages, but the condition is especially severe in piglets, with morbidity and mortality often reaching $100 \%[2,3]$. PED was first reported in England in 1971, but PEDV was isolated for the first time in Belgium in 1978 and designated as prototype coronavirus virulent CV777 [4]. Thus far, PED has been reported in swine-farming

\footnotetext{
*Correspondence: xingli107@gmail.com

${ }^{\dagger}$ Pei-Hua Wang, Ya-Qian Li, Yuan-Qing Pan and Yan-Yan Guo contributed equally to this article

${ }^{1}$ Institutes of Biomedical Sciences, Shanxi University, 92 Wucheng Road, Taiyuan 030006, Shanxi, China

Full list of author information is available at the end of the article
}

countries in Europe, Asia, North America, and South America as one of the most devastating viral diseases of swine in the world, leading to enormous economic loss in the global pork industry $[1,5-8]$.

PEDV is a large enveloped RNA virus. It is a member of the genus Alphacoronavirus within the Coronaviridae family in the order Nidovirales [4]. The PEDV genome RNA is approximately $28 \mathrm{~kb}$ in length with a $5^{\prime}$-cap and a $3^{\prime}$-polyadenylated tail. It contains at least 7 open reading frames (ORF1a, ORF1b, and ORF2-6) [9]. ORFs $1 \mathrm{a}$ and $1 \mathrm{~b}$ encode for viral non-structural proteins (nsps). ORF1a translation produces a replicase polyprotein 1a (ppla) while a -1 ribosomal frame shift (RFS) at the 3 '-end of ORF1a allows the translation of ORF1b through the production of the replicase polyprotein $1 \mathrm{ab}$ (pp1ab). The ppla and pplab are processed during translation by internal proteases into 16 nsps that are mainly responsible for the regulation of

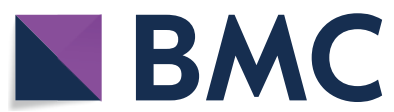

(c) The Author(s) 2021. This article is licensed under a Creative Commons Attribution 4.0 International License, which permits use, sharing, adaptation, distribution and reproduction in any medium or format, as long as you give appropriate credit to the original author(s) and the source, provide a link to the Creative Commons licence, and indicate if changes were made. The images or other third party material in this article are included in the article's Creative Commons licence, unless indicated otherwise in a credit line to the material. If material is not included in the article's Creative Commons licence and your intended use is not permitted by statutory regulation or exceeds the permitted use, you will need to obtain permission directly from the copyright holder. To view a copy of this licence, visit http://creativeco mmons.org/licenses/by/4.0/. The Creative Commons Public Domain Dedication waiver (http://creativecommons.org/publicdomain/ zero/1.0/) applies to the data made available in this article, unless otherwise stated in a credit line to the data. 
transcription, translation, and viral RNA synthesis in the host cells [10]. The remaining ORFs are located in the $3^{\prime}$-proximal region of viral genome and encode four structural proteins including the $150-220 \mathrm{kDa}$ glycosylated spike (S) protein, $20-30 \mathrm{kDa}$ membrane (M) protein, $7 \mathrm{kDa}$ envelope (E) protein, $58 \mathrm{kDa}$ nucleocapsid $(\mathrm{N})$ protein, and one accessory protein $[9,11]$.

The $\mathrm{N}$ protein interacts with viral genomic RNA and then forms the helical nucleocapsid during viral particle assembly [12]. The $M$ protein is also required for the assembly process and can elicit the production of antibodies $[13,14]$. The E protein plays an important role in the budding of the viral particle [15]. The accessory protein encoded by ORF3 is thought to serve as an ion channel and can affect virus production and virulence $[16,17]$.

The $S$ protein of PEDV is the major envelope type I glycoprotein of the virion [18]. It is located on the surface of viral particles and interacts with the cellular receptor during virus entry into host cells [19]. The $\mathrm{S}$ protein forms a homotrimer complex on the surface of coronavirus virion and is responsible for the virus binding to specific cellular receptor [20]. During virus entry into host cell, the $S$ protein monomer is usually cleaved into two subunits, S1 and S2 subunits. The $\mathrm{S} 1$ subunit binds the cellular receptor, which is followed by S2 subunit-mediated fusion of viral and cellular membranes $[20,21]$. There is an extra domain (named Domain 0, D0) located at the $\mathrm{N}$ terminus of S1subunit of PEDV S protein, which preferentially binds to the sialic acid and modulates the host cell tropism of PEDV $[22,23]$. The monomer $\mathrm{S}$ protein of PEDV prototype CV777 contains 1383 amino acid (aa) residues. The cryo-electron microscopy (cryo-EM) structure of this protein in the prefusion conformation was resolved at a resolution of $3.1 \AA$ using the soluble ectodomain [24]. The dissociated S1 subunit trimers adopts a conformation differing from that observed in the intact spike proteins, suggesting that this subunit undergoes conformational rearrangements during virus entry [24].

The PEDV $S$ protein is considered to be a major virulence protein $[25,26]$. The S1 subunit that contains D0 and S1 domain has been shown to be a determinant part of $S$ protein for viral virulence [27]. Deletion of D0 can attenuate viral virulence $[28,29]$ while the variants containing D0-deletion remain capable to enter into the host cells in vivo and in vitro [30,31]. PEDV S protein is also a major protein antigen that elicits the production of neutralizing antibodies [22, 32-34]. Analysis of S1 subunit of PEDV pathogenic strain GDU S protein reveals that both the $\mathrm{N}$-terminal sialic acid binding domain (Domain
0 ) and the C-terminus of S1 subunit contain neutralizing epitopes [22]. Two neutralizing monoclonal antibodies (NmAbs) E10E-1-10 and P4B-1 can recognize epitopes at amino acids (aa) 435-485 and aa 575-639 of PEDV Pintung 52 (PEDV-PT) S protein, respectively [33]. NmAb 2C10 specifically binds to an epitope at aa 1368-1374 of the PEDV CV777 S protein [35]. In addition, multiple neutralizing linear $\mathrm{B}$ cell epitopes have been found at aa 744-774 of S proteins from either PEDV CV777 [36] or CO13 [37]. Therefore, the S protein or its $\mathrm{S} 1$ subunit are the major targets in vaccine research [38-40]. In addition, the $S$ protein of coronaviruses is associated with viral growth adaptation and attenuation [41]. Thus, S gene is always employed in determining the genetic relatedness among PEDV isolates or in developing diagnostic assays [38, 42-45].

The recombination of coronavirus $\mathrm{S}$ genes has been reported. For example, novel variants of canine enteric coronavirus (CCoV), an alphacoronavirus infecting dogs, have been found to result from the $\mathrm{S}$ gene recombination during virus infection $[46,47]$. Li et al. also reported a PEDV strain $\mathrm{CH} / \mathrm{HNQX}-3 / 14$ (GenBank: KR095279.1) that arose from the natural recombination between an attenuated vaccine strains (CV777 or DR13) and a pandemic variant ( $\mathrm{CH} / \mathrm{ZMDZY} / 11)$ [48]. This recombination occurred not only in structural proteincoding region ( $\mathrm{S}$ and $\mathrm{N}$ genes) but also in non-structural protein-coding region (pp1a gene and ORF3) [48]. PEDV TCN/Liaoning25/2018 (GenBank: MK796238.1) was another natural recombinant strain that contains the $\mathrm{S}$ gene from the highly pathogenic $\mathrm{CH} / \mathrm{GDZQ} / 2014$ strain (GenBank:KM242131.1) and the remaining genomic regions from the low pathogenic vaccine isolate SQ2014 (GenBank: KP728470.1) [49].

In China, PED was first reported in Shanghai in 1973 and the causative agent PEDV was confirmed in 1984 [50]. From 1984 to early 2010, PEDV infections in China occurred in pig farms in a sporadic or regional way, thus there were no large-scale outbreaks $[51,52]$. In the early 1990 s, a vaccine containing the inactivated prototype CV777 strain was successfully developed in China and has been widely used in pig farms [50]. However, in late 2010, PED epidemics suddenly occurred in major pig-producing provinces in both vaccinated and non-vaccinated herds, from which highly pathogenic variants of PEDV were identified in China [53]. Since then, severe PEDV epidemics have swept every province or region in China [3, 54-57]. At present, PED still remains to be a devastating threat to swine industry of China [50].

In this study, we reported the characteristics of fulllength $\mathrm{S}$ genes and proteins of PEDV variants isolated in China during 2007-2019. We also found 28 
recombination events in $\mathrm{S}$ genes. The results will provide helpful information for developing the suitable strategies for disease control in China.

\section{Materials and methods Dataset}

A total of 186 complete genomic sequences of PEDVs that were isolated in China from 2007 to 2019 were retrieved from GenBank. The full-length $\mathrm{S}$ protein genes were aligned with Clustal Omega [58] and then analyzed for phylogenetic tree construction and recombination event. The viruses in this report were identified by their GenBank ID, name, country, and year of collection (in a format as GenBank accession number: virus name/country-year of collection). In addition, the sequences of 4 more PEDV strains including virulent CV777 (GenBank ID: AF353511.1), virulent DR13 (GenBank ID: JQ023161.1), and attenuated DR13 (GenBank ID: JQ023162.1) that were isolated in Belgium and South Korea, respectively, and attenuated CV777 (GenBank ID: KT323979) were also included as references in the phylogenetic tree construction and recombination analysis.

\section{Phylogenetic analysis}

A total of 190 sequences of PEDV full-length S genes (186 isolated in China plus 4 reference strains) were used to generate neighbor-joining phylogenetic trees with the MEGA-X software $[59,60]$. The phylogenetic inference was tested with the bootstrap method with 1000 replications. Bootstrap values greater than $70 \%$ were indicated.

\section{Recombination analysis}

The recombination events in the full-length $S$ protein genes were determined by an automatic approach using the RDP4 software package [61]. The potential recombination events were identified by each of 7 algorithms (RDP, GENECONV, Bootscan, MaxChi, Chimaera, SiScan, and PhylPro) embedded in the RDP4 package.

\section{Prediction of linear B cell epitopes}

The linear B cell epitopes on the S protein of PEDV were predicted using BepiPred-2.0 server [62]. The BepiPred-2.0 server is running under IEDB (the immune epitope database) and predicts B-cell epitopes from a protein sequence, using a Random Forest algorithm trained on epitopes and non-epitope amino acids determined from crystal structures. The residues with scores above the threshold value that was set at 0.5 were predicted to be part of an epitope and colored in yellow on the graph (Y-axes depicts residue scores and $\mathrm{X}$-axes indicates residue positions in the sequence). Only conserved fragments of at least 5 amino acid residues that were predicted as potential epitopes by BepiPred- 2.0 were taken into consideration in this study.

\section{Three-dimensional structure prediction}

Tertiary structure modeling of individual regions of PEDV S protein including domain $0, S 1$ domain, and S2 domain was carried out using I-TASER (Iterative Threading ASSEmbly Refinement) server [63-65]. I-TASER is a hierarchical approach to protein structure prediction and structure-based function annotation. It first identifies structural templates from the RCSB protein data bank (PDB) by multiple threading approach LOMETS, with full-length atomic models constructed by iterative template-based fragment assembly simulations.

\section{Statistical analysis}

The statistical analysis was performed with Excel 2019. Data points were reported as the mean \pm standard deviation (SD). The student's $t$-test was used to compare two sets of data.

\section{Results \\ Phylogenetic analysis of full-length S genes of PEDVs isolated in China}

Phylogenetic analyses using the whole-genome or some individual genes were performed to determine the variations and relationships of PEDV isolates [66, 67]. The partial or full-length $S$ gene are known to be suitable loci in the analysis of genetic relatedness and molecular epidemiology of PEDV [42-44]. To thoroughly understand the variation and evolution of PEDVs in China, we constructed a phylogenetic tree based on the full-length $S$ genes of 190 PEDV strains, 186 of which were isolated in China from 2007 to 2019. The prototype strains (virulent CV777 and virulent DR13) and the cell-culture-adapted vaccine strains (attenuated CV777 and attenuated DR13) are included in the analysis as references. As shown in Figure 1 and Additional file 1, the PEDV strains isolated in China can be classified into two genogroups, i.e. GI (classical) and GII (variant). GI genogroup can be further divided into 3 subgroups: GI-a, GI-b, and GI-c. G1a subgroup includes the prototype PEDV strains virulent CV777 and virulent DR13, and 8 Chinese strains including LZC, ZJU/G1 and CHM2013 (Figure 1). GI-b subgroup consists of 3 cell-culture-adapted vaccine strains (attenuated CV777, KT323979.1; attenuated DR13, JQ023162.1; and attenuated PEDV vaccine, 


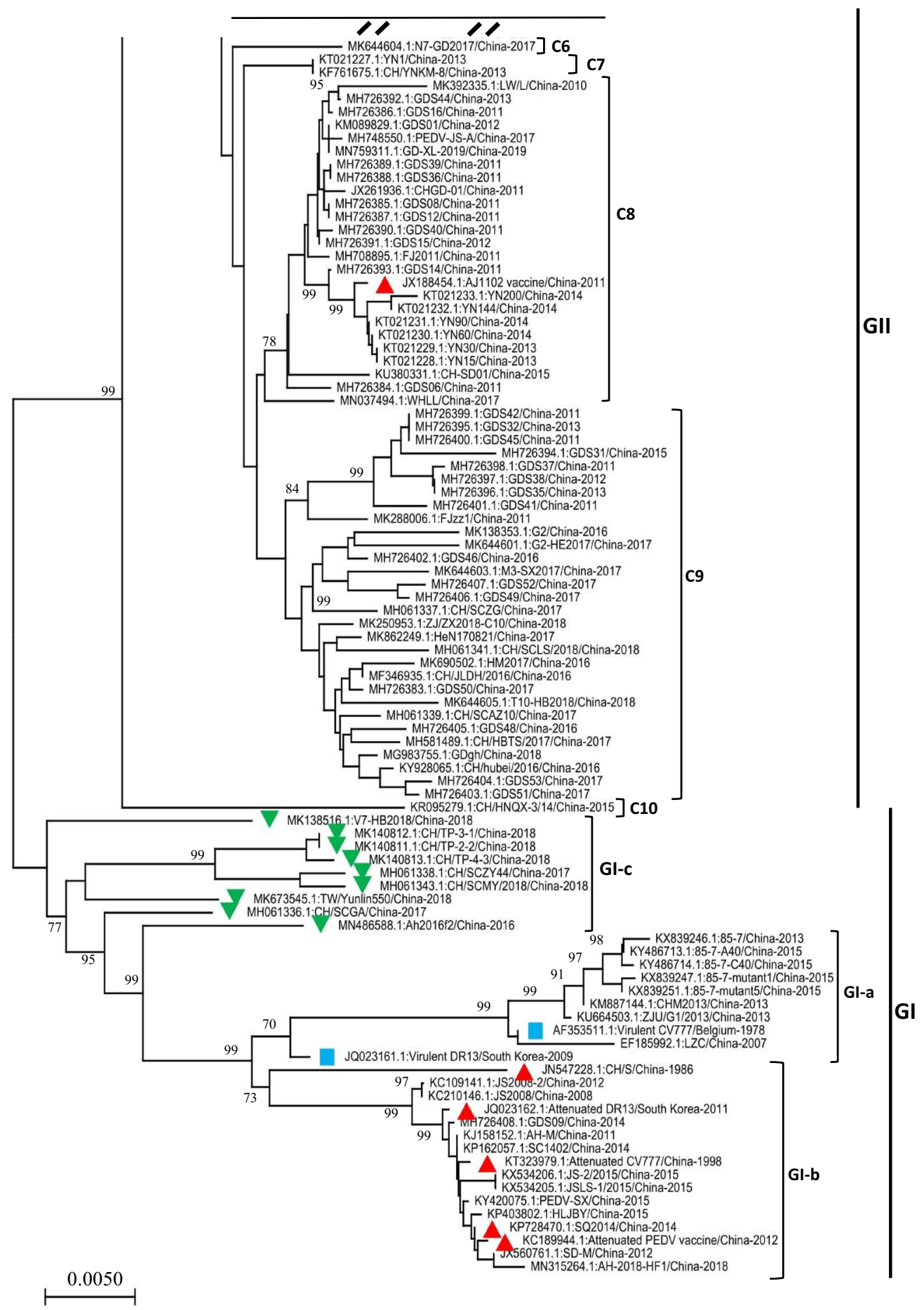

Figure 1 The phylogenetic tree based on the full-length spike gene of PEDVs isolated in China during 2007-2019 (continue on

Additional file 1). Multiple-sequence alignments were performed using Clustal Omega server and the phylogenetic tree was constructed from the aligned nucleotide sequences by using the neighbor-joining method in the MEGA-X software $[59,60]$. The numbers at each branch represent bootstrap values greater than $70 \%$ of 1000 replicates. The scale bars indicate the number of 0.005 inferred substitutions per site. 4 more PEDV strains including virulent CV777 (AF353511.1), virulent DR13 (JQ023161.1), attenuated CV777 (KT323979), and attenuated DR13 (JQ023162.1) were also included as references. The blue squares indicate the virulent strains isolated outside of China. The red triangles indicate the cell culture-adapted vaccine strains or the pandemic strains used to make vaccines. The green upside-down triangles indicate the $\mathrm{Gl}-\mathrm{c}$ viral isolates. 


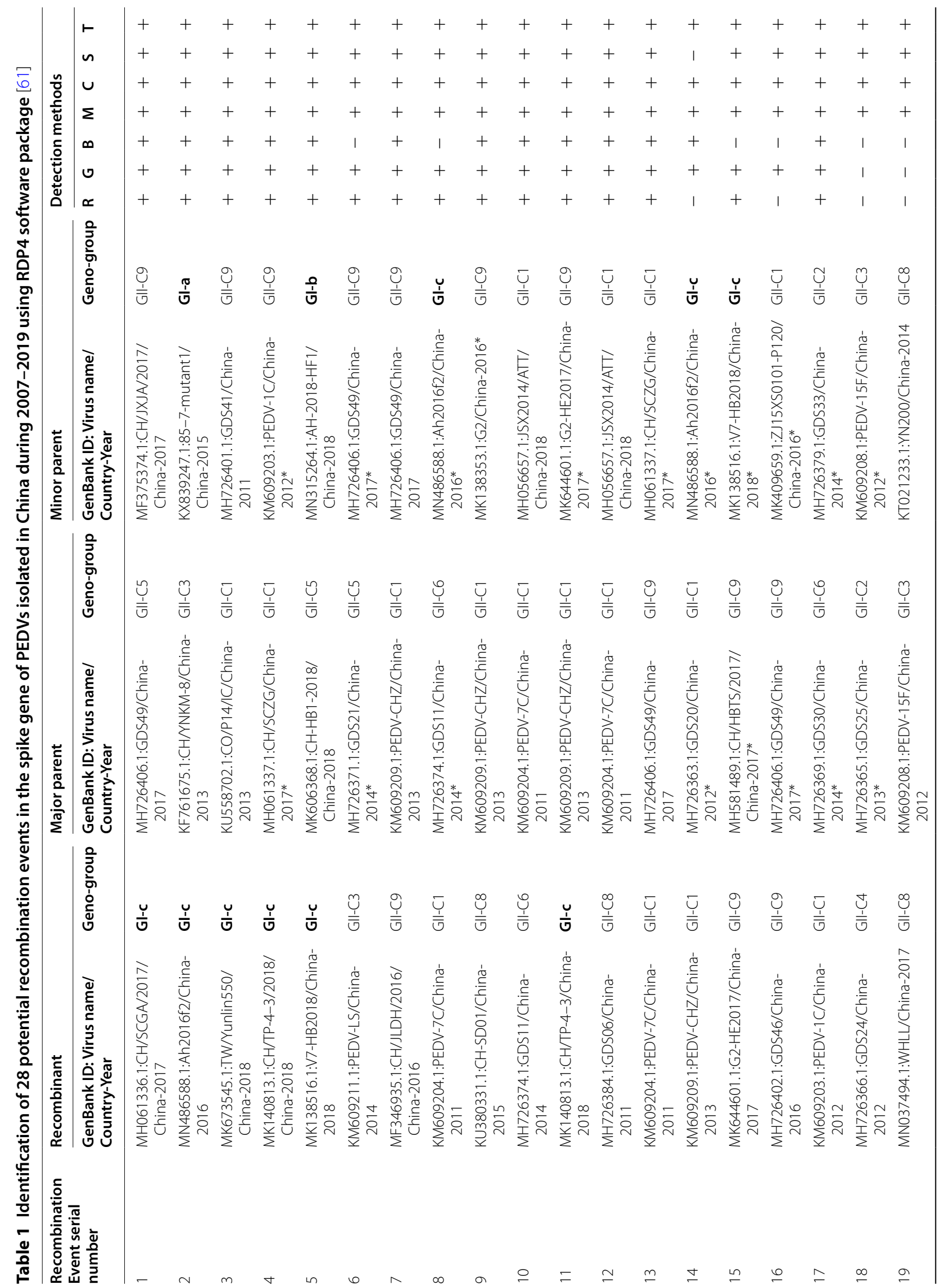




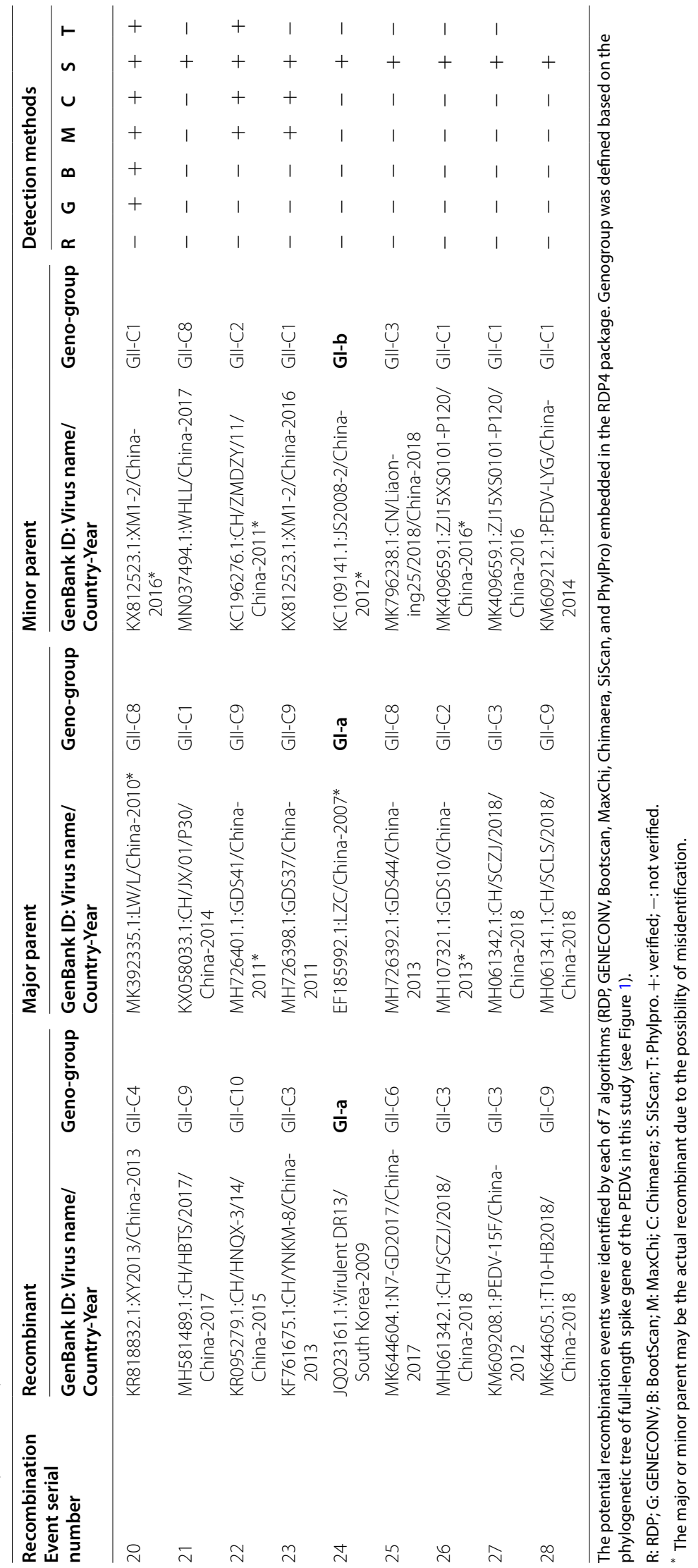


$\mathrm{KC} 189944.1)$ and 13 pandemic classical strains $(\mathrm{CH} / \mathrm{S}$, JS2008, JS2008-2, GDS09, AH-M, SC1402, JS-2/2015, JSLS-1/2015, PEDV-SX, HLJBY, SQ2014, SD-M, and AH-2018-HF1). GI-c subgroup emerged as a new evolutionary branch and consists of 9 PEDV strains that were isolated during 2016-2018. These viral isolates are genetically more distant from those in either GI-a or GI-b subgroups. The most of PEDV strains that were isolated in China during 2007-2019 belong to the GII genogroup, which can be further subdivided into 10 clusters (C1-C10) (Figure 1 and Additional file 1).

\section{Recombination of S genes of PEDVs isolated in China}

In the full-length $S$ gene-based phylogenetic tree, a set of viral isolates that emerged from 2016 to 2018 are sorted into a new subgroup G1-c (Figure 1), implying that the emergence of new PEDV variants will continue and that the virulence-determining $S$ gene may undergo rapid mutation or natural recombination. To identify the recombination events within the $S$ gene of PEDV isolates in China, the full-length $S$ genes included in phylogenetic tree construction (Figure 1) were analyzed using the Recombination Detection Program 4 (RDP4), in which multiple recombination detection methods including RDP, GENECONV, Bootscan, MaxChi, Chimaera, SiScan, and PhylPro were embedded [61]. The recombination analysis reveals that most of PEDV isolates in China seem to arise from 28 potential recombination events in $S$ gene (Table 1, Figure 2). In GI-c subgroup, all of the 9 PEDV isolates (Figure 1) were found to be involved in recombination (Table 1, Figure 2), of which the virus TW/Yunlin550 (GenBank: MK673545.1) has been suggested to arise from the recombination between a Taiwan PEDV GII strain MN and a wild-type GI-a strain virulent DR13 [68]. These results demonstrate that the recombination of $S$ gene is driving the genetic variability of emerging viral isolates in China.

The recombination events occurred mainly in between the PEDVs in GII genogroup (Table 1). Three GI-a viruses are involved in recombination (KX839247.1:85-7-mutant1/China-2015 in event 2; JQ023161.1: Virulent DR13/South Korea-2009 and EF185992.1:LZC/China-2007 in event 24), whereas two GI-b viruses (MN315264.1: AH-2018-HF1/China2018 in event 5 and KC109141.1:JS2008-2/China-2012 in event 24) are found to participate in the recombination (Table 1, Figure 2). We also find that $20 \mathrm{PEDV}$ isolates seem to be involved in multiple recombination events (Table 2).
As shown in Figure 2, in 19 out of 28 recombination events, both beginning and ending breakpoints are located in 5'- or 3'-proximal regions of $S$ gene, which encode the $\mathrm{N}$-terminus or $\mathrm{C}$-terminus of $\mathrm{S}$ protein, respectively. In 9 recombination events, i.e. events 15 , $16,18,20,21,23,24,26$, and 28, the breakpoints are located in the middle region of $S$ gene.

To further explore the recombination of PEDV $\mathrm{S}$ gene, the phylogenetic trees were constructed based on the individual gene fragments that encode different domain of S protein. The fragment nt 1-1011 (relative to the S gene of PEDV virulent CV777, GenBank: AF353511.1) encodes D0 and about 100-amino acids $\mathrm{N}$-terminus of S1 domain of S protein. The fragment nt 1012-2352 encodes mainly the larger part of S1 domain, whereas the fragment nt 2353-4149 encodes the remaining part of S protein including S2 domain, transmembrane domain (TM), and a short cytoplasmic tail (CT) (Figure 2A). As shown in Figure 3, the phylogenetic trees based on the full-length $\mathrm{S}$ gene or individual gene fragments are not superposable to each other. For example, compared with fulllength $\mathrm{S}$ gene-based phylogenetic tree (Figure 3A), the fragment nt 1-1011 of the members of GI-c subgroup (indicated with the green upside-down triangles) are genetically closer to that of virulent viruses (CV777 and DR13; indicated with the blue squares) and 6 vaccine variants (indicated with the red triangles; Figure 3B). However, the fragment nt 1012-2352 (Figure 3C) and fragment nt 2353-4149 (Figure 3D) of the members of GI-c subgroup are genetically far more distant from that of virulent or vaccine variants. These results are reminiscent of the observation that $\mathrm{S}$ gene recombination between GI-a/GI-b and GII variants may result in the emergence of some GI-c viruses.

\section{Variations in linear B cell epitopes of PEDV S protein} Analysis of $\mathrm{S}$ protein sequence of PEDV prototype virulent CV777 in NCBI conserved domain database (CDD) [69-72]) reveals that the S1 subunit contains a conserved S1 domain at aa 231-733, whereas the S2 subunit contains a conserved S2 domain at aa 741-1344 (Figure 4A). The S1 domain can be further divided into four subdomains including S1-NTD (S1 N-terminal domain, aa 231-471), S1-CTD (S1 C-terminal domain, aa 504-637), and Subdomains 1 and 2 (SD-1 and SD-2, aa 638-733) [24]. The Domain 0 in S1 subunit is located upstream of S1 domain [24], where no conserved motifs were detected in the CDD (Figure 4A).

Sequence comparison of the full-length $\mathrm{S}$ proteins reveals that GI-a, GI-b, and GI-c strains share 99\%, 


\section{A

\begin{tabular}{|c|c|c|}
\hline \multicolumn{3}{|c|}{ Spike gene of PEDV virulent CV777 } \\
\hline Domain 0 & S1 domain & S2 domain \\
\hline
\end{tabular}

B MH061336.1: CH/SCGA/2017/China-2017

2 MN486588.1: Ah2016f2/China-2016

3 MK673545.1: TW/Yunlin550/China-2018

4 MK140813.1: CH/TP-4-3/2018/China-2018

5 MK138516.1: V7-HB2018/China-2018

6 KM609211.1: PEDV-LS/China-2014

7 MF346935.1: CH/JLDH/2016/China-2016

8 KM609204.1: PEDV-7C/China-2011

9 KU380331.1: CH-SD01/China-2015

10 MH726374.1: GDS11/China-2014

11 MK140813.1: CH/TP-4-3/China-2018

12 MH726384.1: GDS06/China-2011

13 KM609204.1: PEDV-7C/China-2011

14 KM609209.1: PEDV-CHZ/China-2013

15 MK644601.1: G2-HE2017/China-2017

16 MH726402.1: GDS46/China-2016

17 KM609203.1: PEDV-1C/China-2012

18 MH726366.1: GDS24/China-2012

19 MN037494.1: WHLL/China-2017

20 KR818832.1: XY2013/China-2013

21 MH581489.1: CH/HBTS/2017/China-2017

22 KR095279.1: CH/HNQX-3/14/China-2015
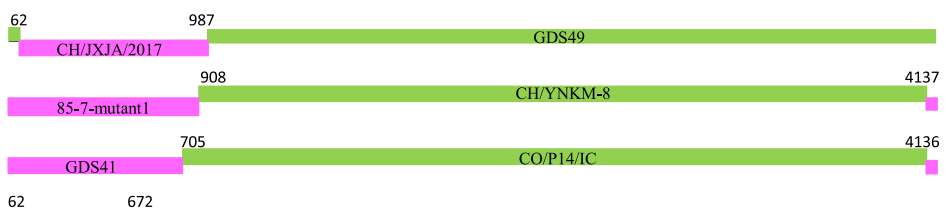

$62 \quad 672 \quad$ CH/SCZG

$128 \quad 669 \quad$ CH-HB1-2018
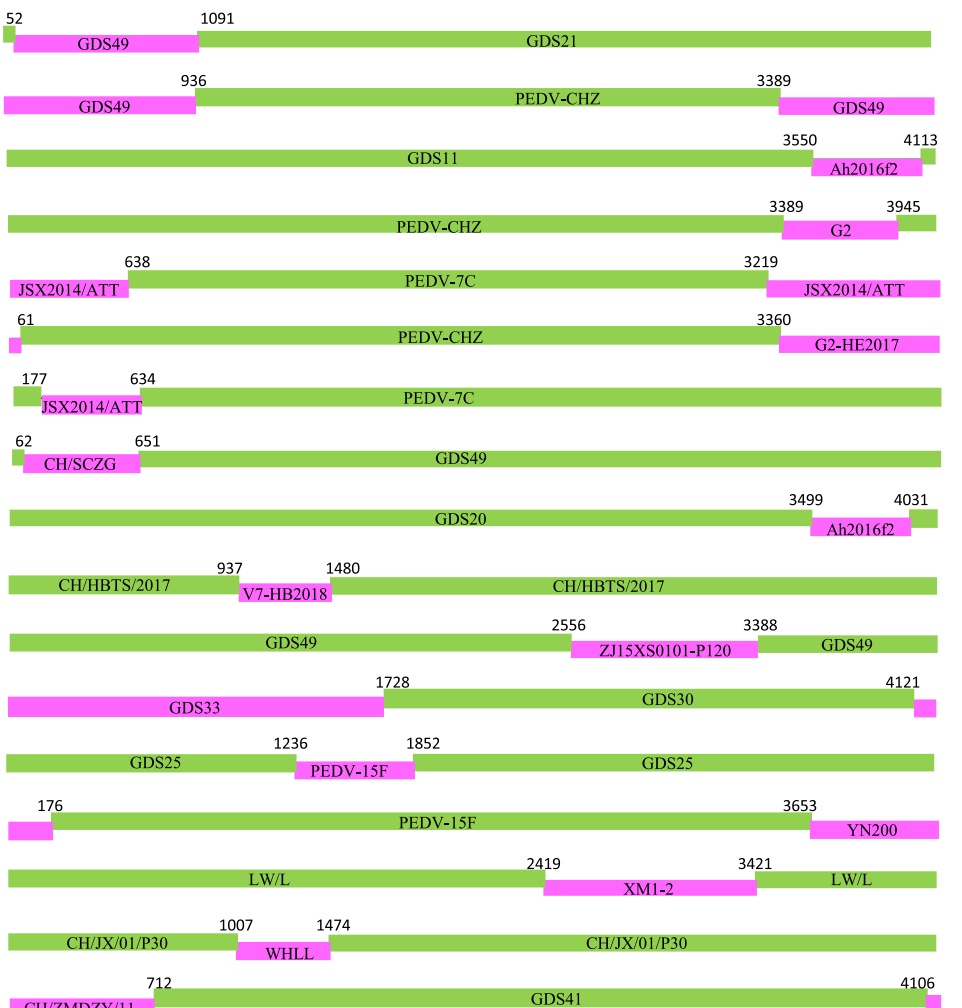

23 KF761675.1:

CH/YNKM-8/China-2013

24 JQ023161.1:

Virulent DR13/South Korea-2009

25 MK644604.1:

N7-GD2017/China-2017

26 MH061342.1: CH/SCZJ/2018/China-2018

27 KM609208.1:

PEDV-15F/China-2012

28 MK644605.1:

10-HB2018/China-2018

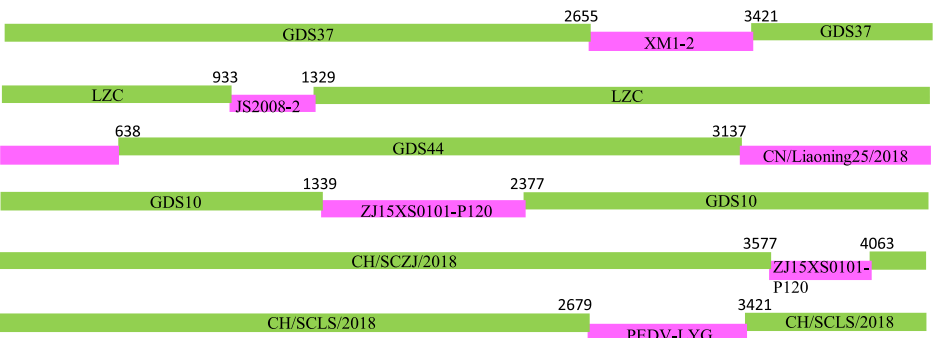

Figure 2 S gene recombination. (A) Diagram showing the full-length S gene of PEDV virulent CV777 and the corresponding regions encoding Domain 0, S1 domain, S2 domain, transmembrane domain (TM), and a short cytoplasmic tail (CT). The S1 domain is composed of four subdomains including S1-NTD (S1 N-terminal domain), S1-CTD (S1 C-terminal domain), SD-1, and SD-2. (B) Schematic representation of potential recombination events listed in Table 1. The recombination event serial number and the description of potential recombinants (GenBank ID: virus name/ country-collection year) are show on the left. The filled pink and green blocks represent the DNA regions from minor or major parent viruses, respectively. The numbers on the top of filled green blocks indicate the nucleotide positions of breakpoints relative to the spike gene sequence of corresponding recombinant viruses on the left. 
Table 2 The PEDVs isolated in China and involved in multiple recombination events in the full-length spike genes

\begin{tabular}{|c|c|c|c|}
\hline GenBank ID: Virus name/country-year & $\begin{array}{l}\text { Recombination Event } \\
\text { serial number (see Table 1) }\end{array}$ & GenBank ID: Virus name/country-year & $\begin{array}{l}\text { Recombination Event } \\
\text { serial number (see } \\
\text { Table 1) }\end{array}$ \\
\hline MN486588.1:Ah2016f2/China-2016 & Event 2, 8, 14 & MH581489.1:CH/HBTS/2017/China-2017 & Event 15, 21 \\
\hline MK140813.1:CH/TP-4-3/2018/China-2018 & Event 4, 11 & MH061342.1:CH/SCZJ/2018/China-2018 & Event 26, 27 \\
\hline MK138516.1:V7-HB2018/China-2018 & Event 5, 15 & KM609208.1:PEDV-15F/China-2012 & Event 18, 19, 27 \\
\hline KM609204.1:PEDV-7C/China-2011 & Event $8,10,12,13$ & MH726406.1:GDS49/China-2017 & Event $1,6,7,13,16$ \\
\hline MH726374.1:GDS11/China-2014 & Event 8,10 & MH061337.1:CH/SCZG/China-2017 & Event 4,13 \\
\hline KM609209.1:PEDV-CHZ/China-2013 & Event $7,9,11,14$ & MH726401.1:GDS41/China-2011 & Event 3, 22 \\
\hline KM609203.1:PEDV-1C/China-2012 & Event 4, 17 & MH056657.1:JSX2014/ATT/China-2018 & Event 10, 12 \\
\hline MK644601.1:G2-HE2017/China-2017 & Event 11,15 & MK409659.1:ZJ15XS0101-P120/China-2016 & Event 16, 26, 27 \\
\hline MN037494.1:WHLL/China-2017 & Event 19, 21 & KX812523.1:XM1-2/China-2016 & Event 20, 23 \\
\hline KF761675.1:CH/YNKM-8/China-2013 & Event 2, 23 & MK409659.1:ZJ15XS0101-P120/China-2016 & Event 26, 27 \\
\hline
\end{tabular}

96\%, and $95 \%$ of amino acid sequence with prototype strain CV777 respectively, but GII strains share only 93\% (Table 3), indicating that GII strains are less closely related to that in GI genogroup. Further amino acid sequence comparison of individual regions of $\mathrm{S}$ protein demonstrates that Domain 0 of $\mathrm{S}$ protein in GI-a, GI-b, GI-c, and GII exhibit 98\%, $96 \%, 93 \%$, and $85 \%$ of identities with that of prototype CV777 (Table 3). When compared with the identities for S1 domain or S2 domain, Domain 0 of $S$ protein is the most variable, particularly for that from GII genogroup (Table 3).

PEDV AJ1102 (GenBank:JX188454) is a GIIC8 strain that was isolated in a PEDV epidemic in China in 2011 [73]. This strain is currently being developed into a potential vaccine [50]. To explore the potential effects of amino acid variations on the antigenicity of $\mathrm{S}$ protein, we compare the linear $\mathrm{B}$ cell epitopes of $S$ proteins between 6 PEDV strains from GI and GII genogroups. The BepiPred-2.0 server was used to predict the potential linear $B$ cell epitopes [62]. As shown in Figure 4B, the fulllength $S$ proteins from GI-a (virulent CV777 and DR13) and G1-b (attenuated CV777 and DR13) subgroups exhibit the similar distribution pattern of predicted B cell epitopes. However, the Domain 0 of GII genogroup strain (AJ1102) shows the most obvious differences in distribution of B cell epitopes when compared with other virus strains (Figure 4B). Furthermore, we used I-TASER server [63-65] to visualize the 3-dimentional structures for Domain $0, \mathrm{~S} 1$ and S2 domains, where the amino acid variations in the $B$ cell epitopes will be structurally compared. As shown in Figure 5A, the Domain 0 of AJ1102 S protein contains a 4-amino acids insertion (58NQGV61), a 1-amino acid insertion (139 N), and a 2-amino acids deletion (in between aa160161) when compared with that of prototype virulent CV777. This insertion-deletion genetic signature of $S$ protein as S INDEL (S insertion-deletion) has been well known for PEDV strains [43, 74]. Those variations are all located in the sequence of predicted epitopes (Figures 5A-C). The mutation of 5 consecutive amino acids (68AGQHP72) and one amino acid mutation $(185 \mathrm{~F})$ lead to the generation of novel potential epitopes in AJ1102 S protein (D0-E3 and D0-E7, respectively) (Figures $5 \mathrm{~A}-\mathrm{C}$ ).

When compared with prototype strain virulent CV777, the amino acid variations in S1 domain of AJ1102 are found in 6 potential epitopes, but does not generate novel epitopes nor eliminate the existing ones (Figure 6A). All those epitopes are located in the coiled region or at the end of $\beta$-sheets (Figure $6 \mathrm{~B}$ ). S1-E6 has been experimentally confirmed to be a linear neutralizing epitope [36].

In $\mathrm{S} 2$ domain of PEDV $\mathrm{S}$ protein, the predicted B cell epitopes S2-E1 to S2-E4 are located at the N-terminal region, whereas epitopes $\mathrm{S} 2-\mathrm{E} 5$ to $\mathrm{S} 2-\mathrm{E} 8$ at the $\mathrm{C}$-terminal region (Figures $7 \mathrm{~A}$ and $\mathrm{B}$ ). 7 of total 8 epitopes are found to be affected by amino acid variations (S2E2 to E8). The epitope S2-E1 is identical between virulent CV777 and AJ1102 strains. This epitope has been experimentally confirmed to be a linear neutralizing epitope [36]. Collectively, the hypervariable Domain 0 of S protein (Figures 4 and 5) may represent one of the major factors driving the antigenic drift of $S$ protein, which may contribute largely to the ineffectiveness of GI genogroup-based vaccines including attenuated PEDV prototype CV777 in protecting piglets from the GII genogroup virus-caused epidemics in China since $2010[3,53,55]$. This situation poses a major challenge to the prevention and control of PED in China. 
A Full-length $\mathrm{S}$ gene

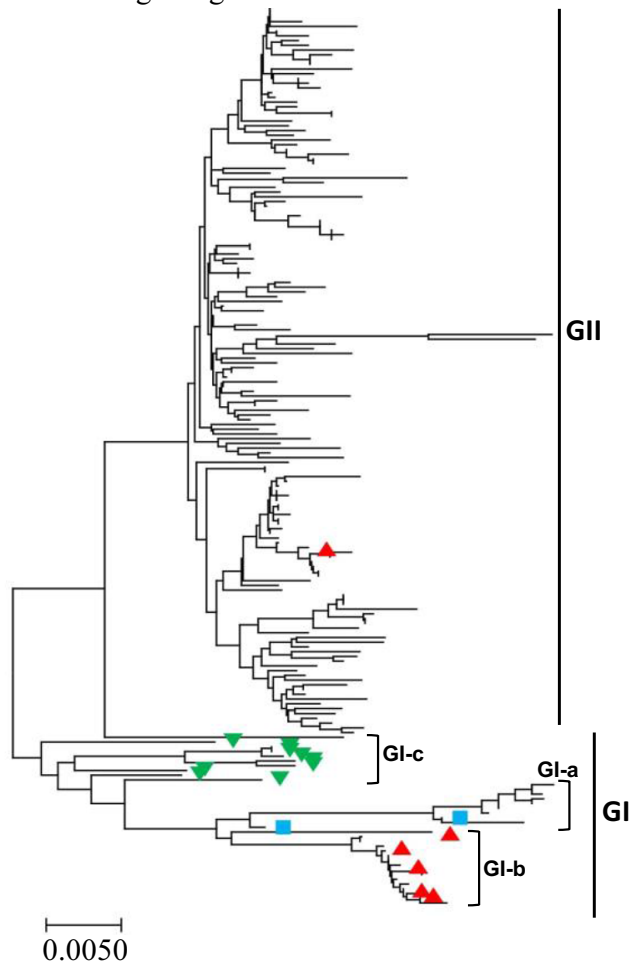

C Fragment nt $1012-2352$

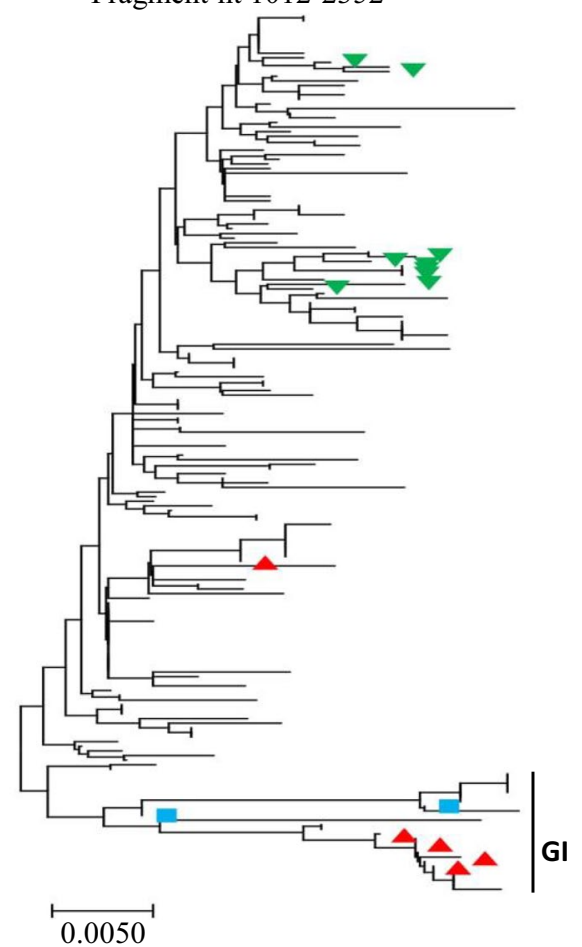

B Fragment nt 1-1011

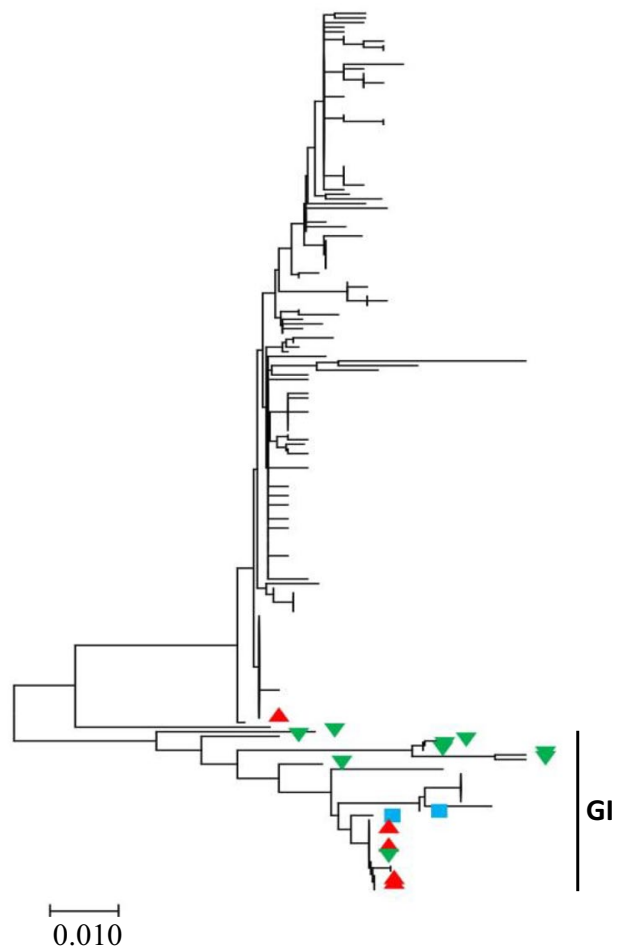

D Fragment nt 2353-4149

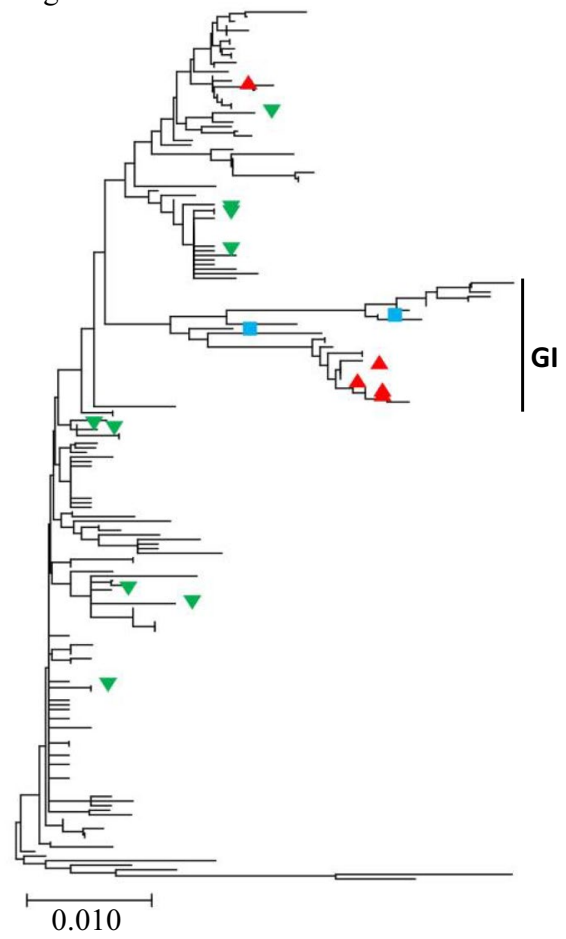

Figure 3 The phylogenetic trees based on the full-length or indicated fragments of PEDV S genes that have been analyzed in Figure 1.

The blue squares indicate the virulent strains isolated outside of China. The red triangles indicate the cell culture-adapted vaccine strains or the pandemic strains used to make vaccines. The green upside-down triangles indicate the $\mathrm{Gl}-\mathrm{c}$ viral isolates. 


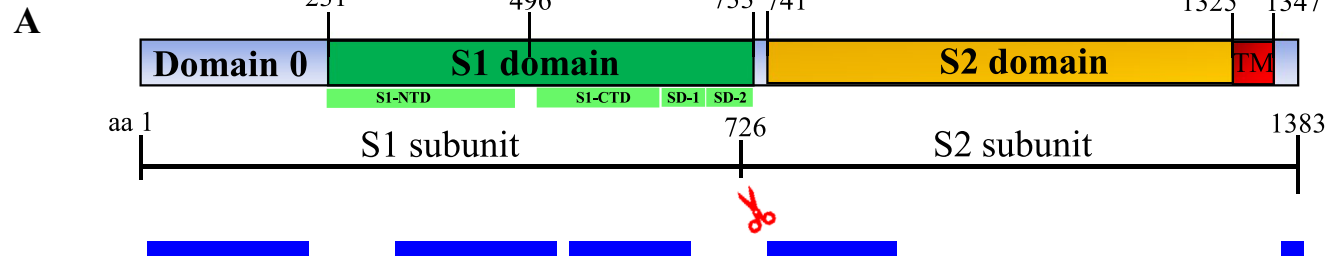

B
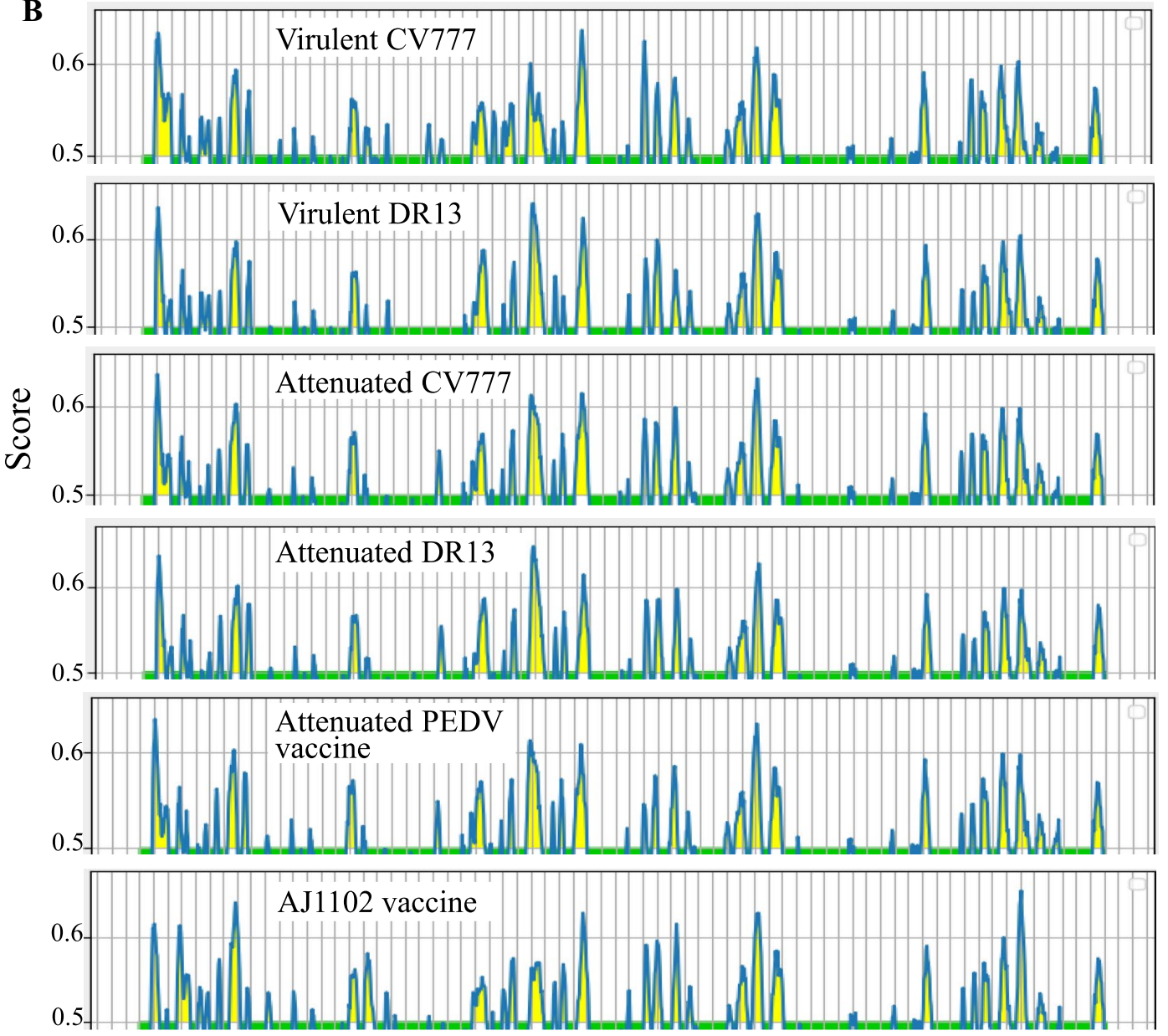

Amino acid position

Figure 4 Linear B cell epitope map of full-length S protein of indicated PEDVs. A Diagram depicting the main features of the PEDV S protein, including: putative cleavage site between S1 and S2 subunits at aa 726, signal peptide (aa 1-18), Domain 0 (aa 19-230), and the transmembrane domain (TM, aa 1325-1347). Functionally conserved S1 domain is at aa 231-733, whereas the S2 domain at aa 741-1344. Four subdomains are found in S1 domain, which include S1-NTD (S1 N-terminal domain, aa 231-471), S1-CTD (S1 C-terminal domain, aa 504-637), and Subdomains 1 and 2 (SD-1 and SD-2, aa 638-733). The numbers indicate the amino acid position relative to the S protein of virulent CV777 (GenBank ID: AF353511.1). The blue blocks represent the relative positions of protein regions where the neutralizing epitopes have been experimentally verified. B The linear B cell epitope map was obtained by using BepiPred-2.0 server. The amino acid residues with scores above the threshold value that was set at 0.5 were predicted to be part of an epitope and colored in yellow on the graph. Y-axes depicts residue scores and X-axes indicates amino acid positions in the sequence, which is also relative to the diagram on the top $(\mathbf{A})$. 
Table 3 Pairwise comparison of the amino acid sequences of full-length $\mathrm{S}$ protein or its individual domains including Domain 0, S1 and S2 domains from GI-a, GI-b, GI-c, and GII genogroup with that of PEDV reference strain virulent CV777 (GenBank ID: AF353511.1)

\begin{tabular}{cllll}
\hline Query: virulent CV777 & Full-length & Domain 0 & S1 domain & S2 domain \\
\hline Gl-a $(n=9)$ & $99.17 \pm 0.29$ & $98.23 \pm 0.54$ & $99.48 \pm 0.42$ & $99.29 \pm 0.24$ \\
Gl-b $(n=16)$ & $96.77 \pm 0.18$ & $96.03 \pm 0.07$ & $96.50 \pm 0.26$ & $97.30 \pm 0.17$ \\
Gl-c $(n=9)$ & $95.13 \pm 0.32$ & $93.07 \pm 1.61$ & $95.01 \pm 0.15$ & $95.99 \pm 0.32$ \\
GII $(n=155)$ & $93.79 \pm 0.49$ & $85.41 \pm 0.86$ & $94.97 \pm 0.43$ & $95.97 \pm 0.68$ \\
\hline
\end{tabular}

The percent amino acid identity (\%) was presented as the mean \pm standard deviation (SD).

\section{Discussion}

The S protein of PEDV plays critical roles in virus infection. It recognizes the cellular receptor via specific interactions during virus entry into the host cells and elicits the production of neutralizing antibodies. The $\mathrm{S}$ protein gene was also used to determine the genetic diversity of viral isolates. To explore the genetic relationships and evolution of PEDVs that circulated in China during 2007-2019, the complete nucleotide and deduced amino acid sequences of a total of 186 full-length $S$ genes were analyzed in this report. Wang et al. [50] previously performed phylogenetic analysis of 62 PEDV strains isolated in China during 2010-2015 on the basis of full-length genomic sequences and sorted those virus strains into two genogroups, GI (classical) and GII (field variant). Each genogroup has two sub-groups: GI-a and GI-b in GI genogroup, GII-a and GII-b in GII genogroup [50]. GI-a subgroup consists of the Chinese classical strains (LZC, CH/S, and CHM2013), along with the prototype strains (virulent CV777 and DR13), whereas GI-b subgroup predominantly contains the cell-culture-adapted vaccine strains (attenuated CV777 and DR13) and other pandemic classical strains (AH-M, SD-M, SQ2014, and SC1402) [50]. The most prevalent strains isolated from outbreaks during 2010-2015 belong to the GII genogroup [50]. In our study, 124 more PEDV strains including 60 viruses isolated in China during 2015-2019 were included in the analysis. In agreement to Wang et al's report [50], most PEDVs isolated from outbreaks after 2015 (but not including 2015) in China belong to the GII genogroup (Figure 1). Only one viral isolate (MN315264.1:AH-2018-HF1/China-2018) is sorted into GI-b subgroup, whereas no new viral isolate belongs to
GI-a subgroup (Figure 1). Additionally, 9 PEDVs isolated during 2016-2018 emerged as a new subgroup in GI genogroup (GI-c), in which virus TW/Yunlin550 has been characterized in a recent report [68]. For GII genogroup, the PEDVs can be further sorted into 10 clusters in our study instead of two subgroups (GII-a and GII-b) classification used by Wang et al. [50].

In this study, we found that the $\mathrm{S}$ gene of PEDVs in China is characterized by high level of the recombination. A total of 28 potential recombination events was found in the $\mathrm{S}$ genes (Figure 2, Table 1, and Table 2). The recombination occurred predominantly between GII genogroup PEDVs, indicating that GII genogroup viruses remain the major threat to the pig farming industry in China. The recombination not only drives the expansion of GII genogroup, but also serves as a critical factor to boost the generation of novel evolutionary lineages, which were classified into GI-c subgroup and resulted from the genetic exchanges between GII variants and GI-a or GI-b variants (Table 1, Figures 2, 3). The emergence of these new recombinants makes the field pandemics more complicated and heterogenous in China, posing extra challenges to the development of effective prevention strategies. The infectivity and pathogenicity of the GI-c recombinants have yet to be explored.

The $\mathrm{S}$ protein is a major antigen eliciting the production of neutralizing antibodies against PEDV. Several regions of the $S$ protein have been found to contain neutralizing epitopes. Li et al. reported that the Domain 0 of the $\mathrm{S}$ protein can elicit neutralizing antibodies [22]. This region is also responsible for the virus binding to the sialic acid during virus entry [75]. Amino acid sequence comparison between GII stain AJ1102 and GI-a prototype virulent CV777 
A

\section{VCV777 18SLPQDVTRCQSTT30 \\ AJ1102 18SLPQDVTRCSANT30}

\section{D0-E5}

VCV777 126DNKTLGPTV-NDVTTGR141

AJ1102 130SIKTLGPTANNDVTTGR146

\section{D0-E2 \\ 55SMN----SSSWYCGTGIETA70 55IGENQGVNSTWYCAGQHPTA 74}

D0-E6

150PAYMRDGKDI159 155 PAHMSE--HS162
D0-E4

82DSGQGFEIGISQEPFDP 98

86RGGHGFEIGISQEPFDP 102

D0-E7

179HFYLKNDWS187

182YFYFKNDWS 190
B
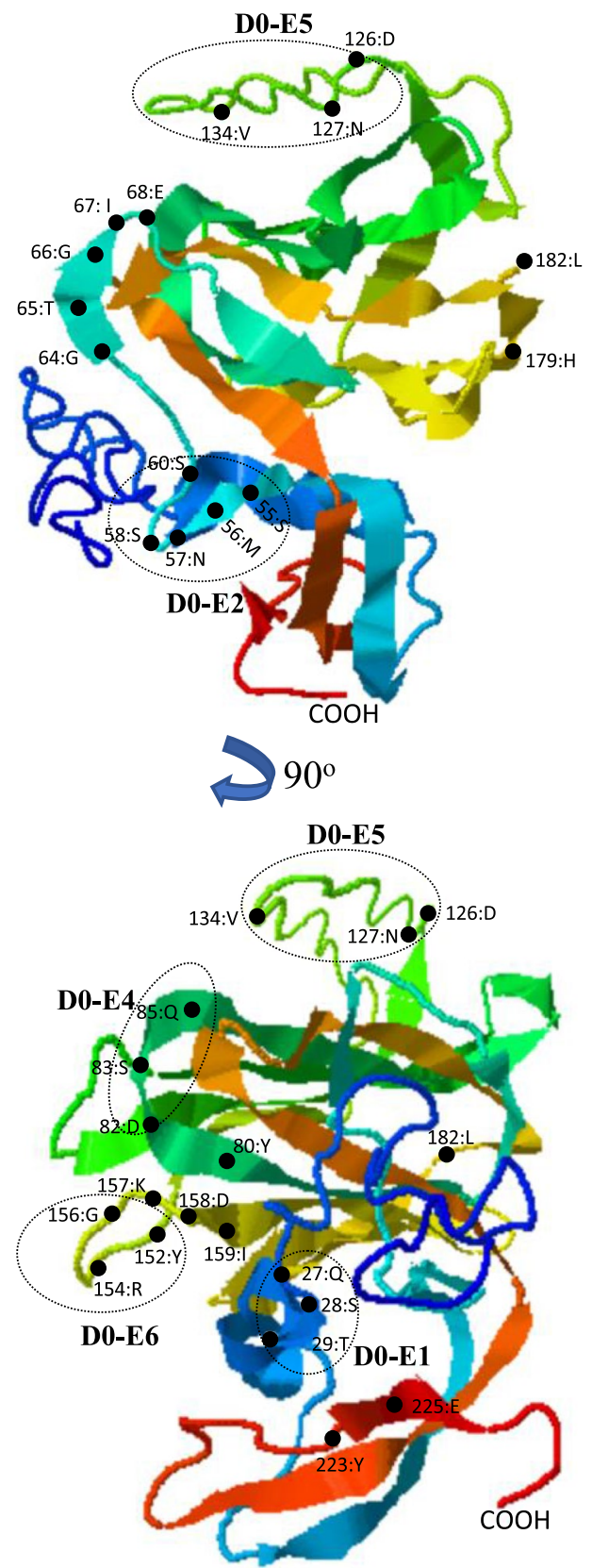

C

D0-E5
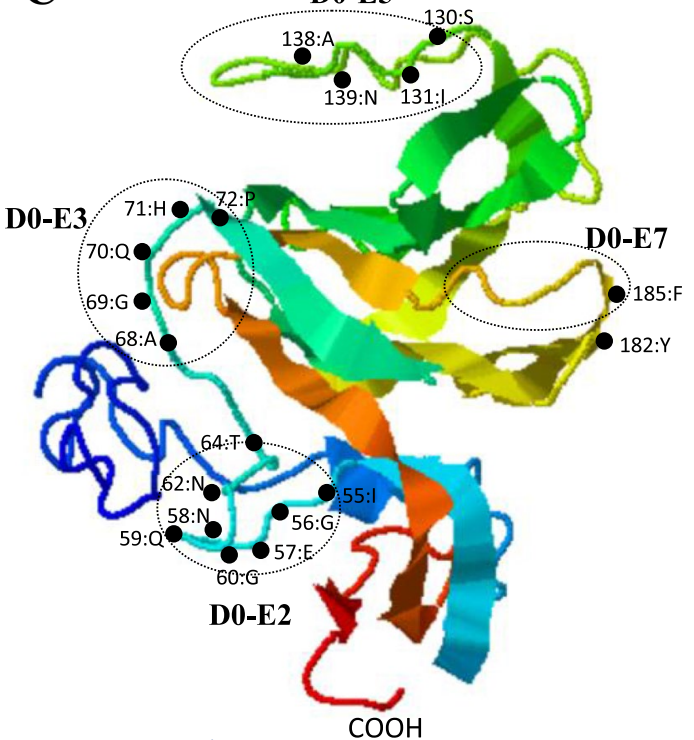

$\$ 90^{\circ}$

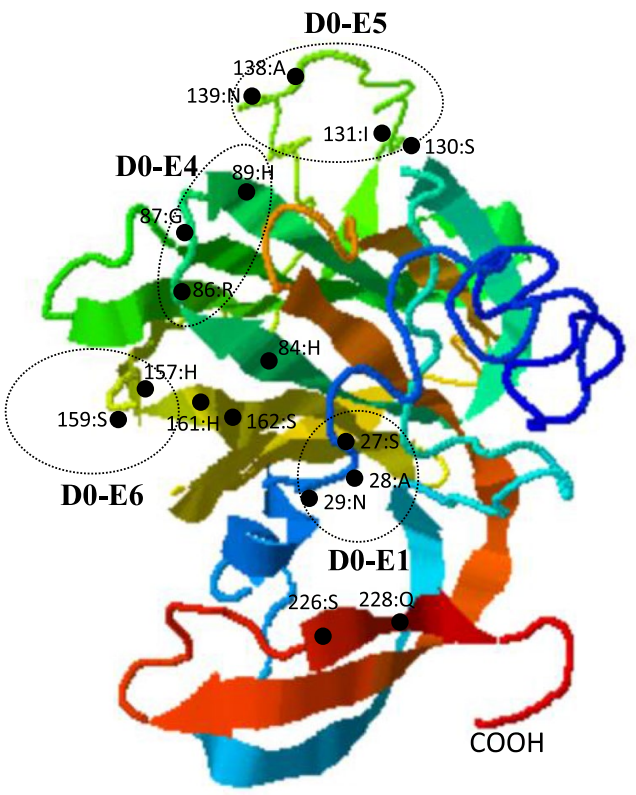

Figure 5 Comparison of linear B cell epitopes affected by amino acid variations in the Domain 0 of S proteins between Gl-a strain virulent CV777 and GII strain AJ1 102. A The amino acid sequence of predicted linear B cell epitopes are shown with red bold letters. The numbers indicate the amino acid positions relative to the full-length S protein of indicated PEDVs. B 3-dimentional view of epitopes in the Domain 0 of virulent CV777 spike protein. C 3-dimentional view of epitopes in the Domain 0 of AJ1102 spike protein. The tertiary structure was modeled by using I-TASER. The individual epitope is circled and the amino acid variations are labeled with black dot. vCV777, virulent CV777. 


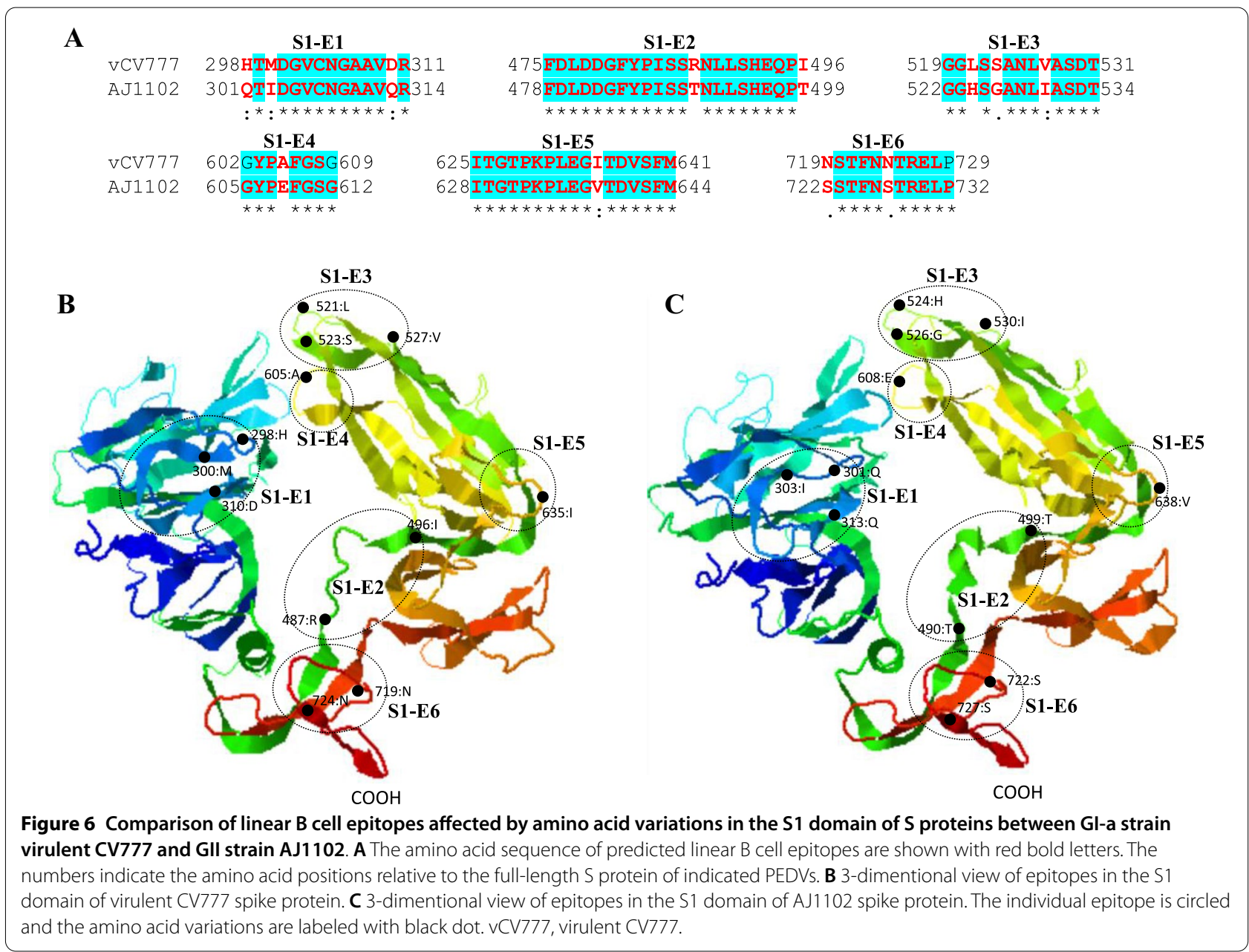

reveals that the antigenicity of this region seems to be mostly varied as amino acid variations dramatically affected the predicted linear epitopes (Figures 4 and 5). The amino acid variations were also found in 13 predicted epitopes in S1 and S2 domains (Figures 6 and 7 , respectively). The epitopes S1-E3, S1-E4, and S1-E5 are located in a neutralizing epitope-containing subdomain [76]. S1-E6, S2-E1, and S2-E2 are located in a region spanning the $\mathrm{S} 1 / \mathrm{S} 2$ junction of PEDV $\mathrm{S}$ protein, to which a series of monoclonal antibodies (mAbs) with neutralizing activity have been identified including SD37-11, SD20-1, SD121-1, SD129-3, SD129-5, SD131-3, SD137-90, SD138-108, and SD142-2 [37]. Collectively, these results suggest that the variations in GII S protein may compromise or even eliminate the neutralizing activities of antibodies elicited by GI S proteins in traditional vaccine strains used in China, which is consistent with the phenomenon that the GI-derived vaccines failed to provide effective protection of piglets from prevailing GII variants-dominated infections since 2010 in China $[38,42,43,77,78]$. Therefore, the GII-based vaccines should be given the priority for pig-farming industry in China.

In summary, the study of $S$ genes and proteins of PEDVs circulating during 2007-2019 in this report demonstrates that GII genogroup and GI-c subgroup represent two major targets for the development of effective prevention strategies in China. The information presented here would benefit the design of novel vaccines for PEDVs circulating in China. 


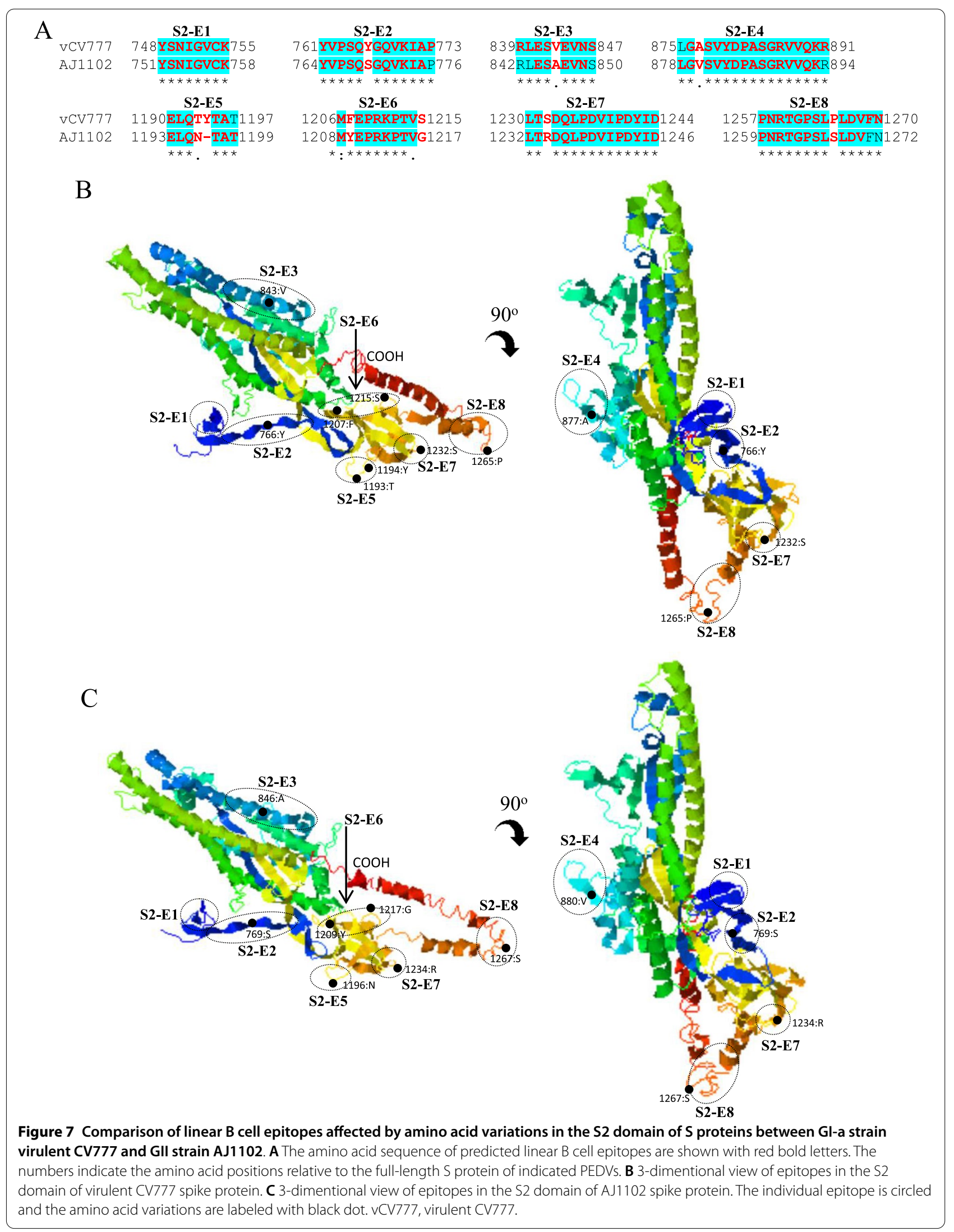




\section{Supplementary Information}

The online version contains supplementary material available at https://doi. org/10.1186/s13567-021-00954-6.

\section{Additional file 1. The phylogenetic tree based on the full-length spike gene of porcine epidemic diarrhea viruses (PEDVs) isolated in China during 2007-2019 (Continue on Fig. 1).}

\section{Acknowledgements}

We thank all the persons who contributed to the collection and production of PEDV genomic sequences in GenBank.

\section{Authors' contributions}

PHW, YYG, YQL, and YQP performed analysis. FG and RZS participated in data analysis. YQL, YQP, and LX wrote the manuscript. PHW, YYG, YQP, and LX revised the manuscript. All authors read and approved the final manuscript.

\section{Availability of data and materials}

The nucleotide and protein sequence data used in this study are available in GenBank.

\section{Declarations}

\section{Consent for publication}

All the authors approved and gave explicit consent for publication of the manuscript.

\section{Competing interests}

The authors declare that they have no competing interests.

\section{Author details}

${ }^{1}$ Institutes of Biomedical Sciences, Shanxi University, 92 Wucheng Road, Taiyuan 030006, Shanxi, China. ${ }^{2}$ Shanxi Provincial Key Laboratory of Medical Molecular Cell Biology, Shanxi University, 92 Wucheng Road, Taiyuan 030006, China. ${ }^{3}$ Shanxi Provincial Key Laboratory for Prevention and Treatment of Major Infectious Diseases, 92 Wucheng Road, Taiyuan 030006, China.

Received: 7 March 2021 Accepted: 17 May 2021

Published online: 15 June 2021

\section{References}

1. Lee C (2015) Porcine epidemic diarrhea virus: an emerging and reemerging epizootic swine virus. Virol J 12:193

2. Shibata I, Tsuda T, Mori M, Ono M, Sueyoshi M, Uruno K (2000) Isolation of porcine epidemic diarrhea virus in porcine cell cultures and experimental infection of pigs of different ages. Vet Microbiol 72:173-182

3. Sun RQ, Cai RJ, Chen YQ, Liang PS, Chen DK, Song CX (2012) Outbreak of porcine epidemic diarrhea in suckling piglets, China. Emerg Infect Dis 18:161-163

4. Pensaert MB, de Bouck P (1978) A new coronavirus-like particle associated with diarrhea in swine. Arch Virol 58:243-247

5. Antas M, Wozniakowski G (2019) Current status of porcine epidemic diarrhoea (PED) in European pigs. J Vet Res 63:465-470

6. Chen X, Zhang XX, Li C, Wang H, Wang H, Meng XZ, Ma J, Ni HB, Zhang X, QiY, Sun D (2019) Epidemiology of porcine epidemic diarrhea virus among Chinese pig populations: a meta-analysis. Microb Pathog 129:43-49

7. Barrera M, Garrido-Haro A, Vaca MS, Granda D, Acosta-Batallas A, Perez L (2017) Tracking the origin and deciphering the phylogenetic relationship of porcine epidemic diarrhea virus in Ecuador. Biomed Res Int 2017:2978718

8. Reveles-Felix S, Carreon-Napoles R, Mendoza-Elvira S, Quintero-RamirezV, Garcia-Sanchez J, Martinez-Bautista R, Saavedra-Montanez M, Mosqueda Gualito JJ, Sanchez-Betancourt JI (2020) Emerging strains of porcine epidemic diarrhoea virus (PEDv) in Mexico. Transbound Emerg Dis 67:1035-1041

9. Kocherhans R, Bridgen A, Ackermann M, Tobler K (2001) Completion of the porcine epidemic diarrhoea coronavirus (PEDV) genome sequence. Virus Genes 23:137-144
10. Snijder EJ, Decroly E, Ziebuhr J (2016) The nonstructural proteins directing coronavirus RNA synthesis and processing. Adv Virus Res 96:59-126

11. Duarte M, Tobler K, Bridgen A, Rasschaert D, Ackermann M, Laude H (1994) Sequence analysis of the porcine epidemic diarrhea virus genome between the nucleocapsid and spike protein genes reveals a polymorphic ORF. Virology 198:466-476

12. McBride R, van Zyl M, Fielding BC (2014) The coronavirus nucleocapsid is a multifunctional protein. Viruses 6:2991-3018

13. de Haan CA, Vennema H, Rottier PJ (2000) Assembly of the coronavirus envelope: homotypic interactions between the M proteins. JVirol 74:4967-4978

14. Zhang Z, Chen J, Shi H, Chen X, Shi D, Feng L, Yang B (2012) Identification of a conserved linear B-cell epitope in the $M$ protein of porcine epidemic diarrhea virus. Virol J 9:225

15. Baudoux P, Carrat C, Besnardeau L, Charley B, Laude H (1998) Coronavirus pseudoparticles formed with recombinant $M$ and $E$ proteins induce alpha interferon synthesis by leukocytes. J Virol 72:8636-8643

16. Song DS, Yang JS, Oh JS, Han JH, Park BK (2003) Differentiation of a Vero cell adapted porcine epidemic diarrhea virus from Korean field strains by restriction fragment length polymorphism analysis of ORF 3. Vaccine 21:1833-1842

17. Wang K, Lu W, Chen J, Xie S, Shi H, Hsu H, Yu W, Xu K, Bian C, Fischer WB, SchwarzW, Feng L, Sun B (2012) PEDV ORF3 encodes an ion channel protein and regulates virus production. FEBS Lett 586:384-391

18. Bosch BJ, van der Zee R, de Haan CA, Rottier PJ (2003) The coronavirus spike protein is a class I virus fusion protein: structural and functional characterization of the fusion core complex. JVirol 77:8801-8811

19. LiW, van Kuppeveld FJM, He Q, Rottier PJM, Bosch BJ (2016) Cellular entry of the porcine epidemic diarrhea virus. Virus Res 226:117-127

20. Li F (2016) Structure, function, and evolution of coronavirus spike proteins Annu Rev Virol 3:237-261

21. Duarte M, Laude H (1994) Sequence of the spike protein of the porcine epidemic diarrhoea virus. J Gen Virol 75:1195-1200

22. Li C, Li W, Lucio de Esesarte E, Guo H, van den Elzen P, Aarts E, van den Born E, Rottier PJM, Bosch BJ (2017) Cell attachment domains of the porcine epidemic diarrhea virus spike protein are key targets of neutralizing antibodies. J Virol 91:e00273-e317

23. Liu C, Tang J, Ma Y, Liang X, Yang Y, Peng G, Qi Q, Jiang S, Li J, Du L, Li F (2015) Receptor usage and cell entry of porcine epidemic diarrhea coronavirus. J Virol 89:6121-6125

24. Wrapp D, McLellan JS (2019) The 3.1-angstrom cryo-electron microscopy structure of the porcine epidemic diarrhea virus spike protein in the prefusion conformation. J Virol 93:e00923-e1019

25. Wang D, Ge X, Chen D, Li J, Cai Y, Deng J, Zhou L, Guo X, Han J, Yang H (2018) The $S$ gene is necessary but not sufficient for the virulence of porcine epidemic diarrhea virus novel variant strain BJ2011C. JVirol 92:e00603-e618

26. Kao CF, Chang HW (2019) Investigation of the role of the spike protein in reversing the virulence of the highly virulent Taiwan porcine epidemic diarrhea virus pintung 52 strains and its attenuated counterpart. Viruses 12:41

27. Suzuki T, Terada Y, Enjuanes L, Ohashi S, Kamitani W (2018) S1 subunit of spike protein from a current highly virulent porcine epidemic diarrhea virus is an important determinant of virulence in piglets. Viruses 10:467

28. Hou Y, Lin CM, Yokoyama M, Yount BL, Marthaler D, Douglas AL, Ghimire S, Qin Y, Baric RS, Saif L, Wang Q (2017) Deletion of a 197-amino-acid region in the $\mathrm{N}$-terminal domain of spike protein attenuates porcine epidemic diarrhea virus in piglets. J Virol 91:e00227-e317

29. Suzuki T, Shibahara T, Yamaguchi R, Nakade K, Yamamoto T, Miyazaki A, Ohashi S (2016) Pig epidemic diarrhoea virus S gene variant with a large deletion nonlethal to colostrum-deprived newborn piglets. J Gen Virol 97:1823-1828

30. Diep NV, Norimine J, Sueyoshi M, Lan NT, Yamaguchi R (2017) Novel Porcine Epidemic Diarrhea Virus (PEDV) Variants with large deletions in the spike (S) gene coexist with PEDV strains possessing an intact $S$ gene in domestic pigs in Japan: a new disease situation. PLoS One 12:e0170126

31. Oka T, Saif $L$, Marthaler D, Esseili MA, Meulia T, Lin CM, Vlasova AN, Jung K, Zhang Y, Wang Q (2014) Cell culture isolation and sequence analysis of genetically diverse US porcine epidemic diarrhea virus strains including a novel strain with a large deletion in the spike gene. Vet Microbiol 173:258-269

32. Gong L, Lin Y, Qin J, Li Q, Xue C, Cao Y (2018) Neutralizing antibodies against porcine epidemic diarrhea virus block virus attachment and internalization. Virol J 15:133 
33. Chang CY, Cheng IC, Chang YC, Tsai PS, Lai SY, Huang YL, Jeng CR, Pang VF, Chang HW (2019) Identification of neutralizing monoclonal antibodies targeting novel conformational epitopes of the porcine epidemic diarrhoea virus spike protein. Sci Rep 9:2529

34. Kirchdoerfer RN, Bhandari M, Martini O, Sewall LM, Bangaru S, Yoon KJ, Ward $A B(2020)$ Structure and immune recognition of the porcine epidemic diarrhea virus spike protein. Structure 29:385-392

35. Cruz DJ, Kim CJ, Shin HJ (2006) Phage-displayed peptides having antigenic similarities with porcine epidemic diarrhea virus (PEDV) neutralizing epitopes. Virology 354:28-34

36. Sun D, Feng L, Shi H, Chen J, Cui X, Chen H, Liu S, Tong Y, Wang Y, Tong G (2008) Identification of two novel $B$ cell epitopes on porcine epidemic diarrhea virus spike protein. Vet Microbiol 131:73-81

37. Okda FA, Lawson S, Singrey A, Nelson J, Hain KS, Joshi LR, ChristopherHennings J, Nelson EA, Diel DG (2017) The S2 glycoprotein subunit of porcine epidemic diarrhea virus contains immunodominant neutralizing epitopes. Virology 509:185-194

38. Oh J, Lee KW, Choi HW, Lee C (2014) Immunogenicity and protective efficacy of recombinant S1 domain of the porcine epidemic diarrhea virus spike protein. Arch Virol 159:2977-2987

39. Liu DQ, Ge JW, Qiao XY, Jiang YP, Liu SM, Li YJ (2012) High-level mucosal and systemic immune responses induced by oral administration with Lactobacillus-expressed porcine epidemic diarrhea virus (PEDV) S1 region combined with Lactobacillus-expressed N protein. Appl Microbiol Biotechnol 93:2437-2446

40. Meng F, Ren Y, Suo S, Sun X, Li X, Li P, Yang W, Li G, Li L, Schwegmann-Wessels C, Herrler G, Ren X (2013) Evaluation on the efficacy and immunogenicity of recombinant DNA plasmids expressing spike genes from porcine transmissible gastroenteritis virus and porcine epidemic diarrhea virus. PLoS One 8:e57468

41. Sato T, Takeyama N, Katsumata A, Tuchiya K, Kodama T, Kusanagi K (2011) Mutations in the spike gene of porcine epidemic diarrhea virus associated with growth adaptation in vitro and attenuation of virulence in vivo. Virus Genes 43:72-78

42. Lee S, Lee C (2014) Outbreak-related porcine epidemic diarrhea virus strains similar to US strains, South Korea, 2013. Emerg Infect Dis 20:1223-1226

43. Lee DK, Park CK, Kim SH, Lee C (2010) Heterogeneity in spike protein genes of porcine epidemic diarrhea viruses isolated in Korea. Virus Res 149:175-182

44. Chen Q, Li G, Stasko J, Thomas JT, Stensland WR, Pillatzki AE, Gauger PC, Schwartz KJ, Madson D, Yoon KJ, Stevenson GW, Burrough ER, Harmon KM, Main RG, Zhang J (2014) Isolation and characterization of porcine epidemic diarrhea viruses associated with the 2013 disease outbreak among swine in the United States. J Clin Microbiol 52:234-243

45. Gerber PF, Gong Q, Huang YW, Wang C, Holtkamp D, Opriessnig T (2014) Detection of antibodies against porcine epidemic diarrhea virus in serum and colostrum by indirect ELISA. Vet J 202:33-36

46. Licitra BN, Duhamel GE, Whittaker GR (2014) Canine enteric coronaviruses: emerging viral pathogens with distinct recombinant spike proteins. Viruses 6:3363-3376

47. Regan AD, Millet JK, Tse LP, Chillag Z, Rinaldi VD, Licitra BN, Dubovi E, Town CD, Whittaker GR (2012) Characterization of a recombinant canine coronavirus with a distinct receptor-binding (S1) domain. Virology 430:90-99

48. Li R, Qiao S, Yang Y, Guo J, Xie S, Zhou E, Zhang G (2016) Genome sequencing and analysis of a novel recombinant porcine epidemic diarrhea virus strain from Henan, China. Virus Genes 52:91-98

49. Wang H, Zhang L, Shang Y, Tan R, Ji M, Yue X, Wang N, Liu J, Wang C, Li Y, Zhou T (2020) Emergence and evolution of highly pathogenic porcine epidemic diarrhea virus by natural recombination of a low pathogenic vaccine isolate and a highly pathogenic strain in the spike gene. Virus Evol 6:veaa049

50. Wang D, Fang L, Xiao S (2016) Porcine epidemic diarrhea in China. Virus Res 226:7-13

51. Chen J, Wang C, Shi H, Qiu H, Liu S, Chen X, Zhang Z, Feng L (2010) Molecular epidemiology of porcine epidemic diarrhea virus in China. Arch Virol 155:1471-1476

52. Chen JF, Sun DB, Wang CB, Shi HY, Cui XC, Liu SW, Qiu HJ, Feng L (2008) Molecular characterization and phylogenetic analysis of membrane protein genes of porcine epidemic diarrhea virus isolates in China. Virus Genes 36:355-364

53. LiW, Li H, LiuY, Pan Y, Deng F, Song Y, Tang X, He Q (2012) New variants of porcine epidemic diarrhea virus, China, 2011. Emerg Infect Dis 18:1350-1353
54. Tian PF, Jin YL, Xing G, Qv LL, Huang YW, Zhou JY (2014) Evidence of recombinant strains of porcine epidemic diarrhea virus, United States, 2013. Emerg Infect Dis 20:1735-1738

55. Wang XM, Niu BB, Yan H, Gao DS, Yang X, Chen L, Chang HT, Zhao J, Wang CQ (2013) Genetic properties of endemic Chinese porcine epidemic diarrhea virus strains isolated since 2010. Arch Virol 158:2487-2494

56. Gao X, Zhang L, Jiang X, Mehmood K, Wang L, Tong X, Wang M, Zhang H, Li $J$ (2019) Porcine epidemic diarrhea: an emerging disease in Tibetan pigs in Tibet, China. Trop Anim Health Prod 51:491-494

57. Qin S, Hu C, Yang D, Wu J, Yue H, Tang C, Zhang B (2019) Emergence of porcine epidemic diarrhea viruses with the novel $S$ genes in Tibetan pigs in the Qinghai-Tibetan plateau in China. Virus Res 270:197652

58. Sievers F, Wilm A, Dineen D, Gibson TJ, Karplus K, Li W, Lopez R, McWilliam H, Remmert M, Soding J, Thompson JD, Higgins DG (2011) Fast, scalable generation of high-quality protein multiple sequence alignments using Clustal Omega. Mol Syst Biol 7:539

59. Kumar S, Stecher G, Li M, Knyaz C, Tamura K (2018) MEGA X: Molecular evolutionary genetics analysis across computing platforms. Mol Biol Evol 35:1547-1549

60. Tamura K, Nei M, Kumar S (2004) Prospects for inferring very large phylogenies by using the neighbor-joining method. Proc Natl Acad Sci USA 101:11030-11035

61. Martin DP, Murrell B, Golden M, Khoosal A, Muhire B (2015) RDP4: Detection and analysis of recombination patterns in virus genomes. Virus Evol 1:vev003

62. Jespersen MC, Peters B, Nielsen M, Marcatili P (2017) BepiPred-2.0: improving sequence-based B-cell epitope prediction using conformational epitopes. Nucleic Acids Res 45:W24-W29

63. Yang J, Yan R, Roy A, Xu D, Poisson J, Zhang Y (2015) The I-TASSER Suite: protein structure and function prediction. Nat Methods 12:7-8

64. Roy A, Kucukural A, Zhang Y (2010) I-TASSER: a unified platform for automated protein structure and function prediction. Nat Protoc 5:725-738

65. Yang J, Zhang Y (2015) I-TASSER server: new development for protein structure and function predictions. Nucleic Acids Res 43:W174-181

66. Park SJ, Song DS, Park BK (2013) Molecular epidemiology and phylogenetic analysis of porcine epidemic diarrhea virus (PEDV) field isolates in Korea. Arch Virol 158:1533-1541

67. Jiang C, Zhang X, Han J, He H, Zhang C, Zhang H, Jin J, Wang L, Ge B, Wang Y, Liu Y (2018) Molecular characterization and phylogenetic analysis of porcine epidemic diarrhea virus isolates in Eastern China. J Infect Dev Ctries 12:1124-1133

68. Hsueh FC, Lin CN, Chiou HY, Chia MY, Chiou MT, Haga T, Kao CF, Chang YC, Chang CY, Jeng CR, Chang HW (2020) Updated phylogenetic analysis of the spike gene and identification of a novel recombinant porcine epidemic diarrhoea virus strain in Taiwan. Transbound Emerg Dis 67:417-430

69. Lu S, Wang J, Chitsaz F, Derbyshire MK, Geer RC, Gonzales NR, Gwadz M, Hurwitz DI, Marchler GH, Song JS, Thanki N, Yamashita RA, Yang M, Zhang D, Zheng C, Lanczycki CJ, Marchler-Bauer A (2020) CDD/SPARCLE: the conserved domain database in 2020. Nucleic Acids Res 48:D265-D268

70. Marchler-Bauer A, Bo Y, Han L, He J, Lanczycki CJ, Lu S, Chitsaz F, Derbyshire MK, Geer RC, Gonzales NR, Gwadz M, Hurwitz DI, Lu F, Marchler GH, Song JS, Thanki N, Wang Z, Yamashita RA, Zhang D, Zheng C, Geer LY, Bryant SH (2017) CDD/ SPARCLE: functional classification of proteins via subfamily domain architectures. Nucleic Acids Res 45:D200-D203

71. Yang M, Derbyshire MK, Yamashita RA, Marchler-Bauer A (2020) NCBl's conserved domain database and tools for protein domain analysis. Curr Protoc Bioinform 69:e90

72. Marchler-Bauer A, Derbyshire MK, Gonzales NR, Lu S, Chitsaz F, Geer LY, Geer RC, He J, Gwadz M, Hurwitz DI, Lanczycki CJ, Lu F, Marchler GH, Song JS, Thanki N, Wang Z, Yamashita RA, Zhang D, Zheng C, Bryant SH (2015) CDD: NCBl's conserved domain database. Nucleic Acids Res 43:D222-D226

73. Bi J, Zeng S, Xiao S, Chen H, Fang L (2012) Complete genome sequence of porcine epidemic diarrhea virus strain AJ1 102 isolated from a suckling piglet with acute diarrhea in China. JVirol 86:10910-10911

74. Jung $K$, Saif $\sqcup$, Wang $Q$ (2020) Porcine epidemic diarrhea virus (PEDV): An update on etiology, transmission, pathogenesis, and prevention and control. Virus Res 286:198045

75. Hou XL, Yu LY, Liu J, Wang GH (2007) Surface-displayed porcine epidemic diarrhea viral (PEDV) antigens on lactic acid bacteria. Vaccine 26:24-31 
76. Chang SH, Bae JL, Kang TJ, Kim J, Chung GH, Lim CW, Laude H, Yang MS, Jang YS (2002) Identification of the epitope region capable of inducing neutralizing antibodies against the porcine epidemic diarrhea virus. Mol Cells 14:295-299

77. Lee S, Kim Y, Lee C (2015) Isolation and characterization of a Korean porcine epidemic diarrhea virus strain KNU-141112. Virus Res 208:215-224

78. Kim SH, Lee JM, Jung J, Kim IJ, Hyun BH, Kim HI, Park CK, Oem JK, Kim YH, Lee MH, Lee KK (2015) Genetic characterization of porcine epidemic diarrhea virus in Korea from 1998 to 2013. Arch Virol 160:1055-1064

\section{Publisher's Note}

Springer Nature remains neutral with regard to jurisdictional claims in published maps and institutional affiliations.
Ready to submit your research? Choose BMC and benefit from:

- fast, convenient online submission

- thorough peer review by experienced researchers in your field

- rapid publication on acceptance

- support for research data, including large and complex data types

- gold Open Access which fosters wider collaboration and increased citations

- maximum visibility for your research: over $100 \mathrm{M}$ website views per year

At BMC, research is always in progress.

Learn more biomedcentral.com/submissions 